\title{
Author Correction: Addressing violence against children online and offline
}

Daniel Kardefelt-Winther (D) and Catherine Maternowska

Correction to: Nature Human Behaviour https://doi.org/10.1038/s41562-019-0791-3, published online 12 December 2019.

In the version of this article initially published online, the following sentence was omitted from the Acknowledgments: "Finally, we deeply value the insightful and critical reflections provided by E. Allen, Chair of the Board of the WePROTECT Global Alliance, who helped inform our thinking at the early stage." The error has been corrected in the PDF and HTML versions of this article.

Published online: 6 February 2020

https://doi.org/10.1038/s41562-020-0825-X

๑) Springer Nature Limited 2020 